\title{
Analytical Research on Method for Applying Interfacial Fracture Mechanics to Evaluate Strength of Cementitious Adhesive Interfaces for Thin Structural Finish Details
}

\author{
Tsugumichi Watanabe \\ Osaka City University \\ Japan
}

\section{Introduction}

Concrete structures often incorporate large numbers of thin-section finishing components that are bonded or joined to the concrete with inorganic cement-type adhesives, such as cement mortar, when wet construction methods are used. These components, usually ceramic tile or other finished products, are emplaced by experienced workmen to create exterior finishing products using plastering cement mortar as adhesive. These exterior layers are typically 5-30 mm thick. Cement mortar finishing products are normally singlelayer, while ceramic tile finishing products usually consist of two layers, with the tile emplaced atop adhesive cement mortar. One of the typical signs of decay for these components is delamination at the interface of the finishing product and the concrete structure. Delamination is usually attributed to high shear stresses and fractures at the interface caused by elastic and creep strain in the concrete due to the weight of the structure, and expansion-contraction strains caused by environmental variations.

Because of this, Japanese institutions have begun testing samples of thin sections attached to concrete with cement mortar using the method shown in Figure 1. An axial compressive load is then applied to exert a shear stress on the interface between the two materials. This approach is simple and provides a macroscopic measure of the shear resistance at the interface while the concrete is under compressive loading. An example of the test results obtained from ceramic tile finishing products is shown in Figure 2. This shows the how the strain on the lateral face of the tile varies with the mean stress at the loaded face of the concrete. Since the shear stress is concentrated at the edge of the interface between the finishing product and the underlying concrete, this is where delamination between the two bodies normally begins. Specifically, at the edge of the interface between the concrete and the cement mortar used as adhesive. Once the delamination propagates laterally out to the edges of the interface, where the strain is measured in these observations, the connection fails and the indicated strain terminates abruptly. These phenomena are often seen when separation has occurred due to extremely brittle fracture conditions at the interface. However, a method for evaluating the interface strength under the installed thin finishing components has yet to be developed.

It is possible that adhesive design technologies based on linear elastic interfacial fracture mechanics could prove useful for assessing the fracture strength of the cement-type 
adhesive at the interface when it fails due to excessive brittleness, i.e., unstable fracture. If so, it will first be necessary to not only describe the stress field in the vicinity of the finishing product interface, but also to determine methods for calculating the stress singularity parameters governing interfacial fracture mechanics of the situation, and to subsequently validate the effectiveness of those parameters.

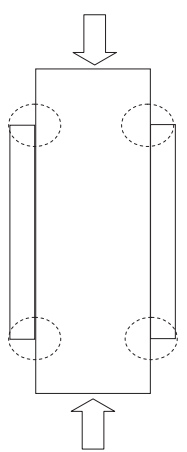

(a) Two-sided test

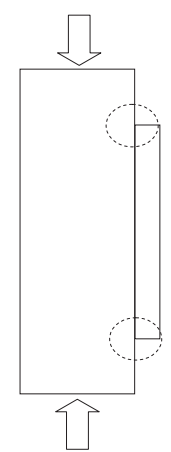

(b) One-sided test delamination
CIRCLE: Assumed location of initial

$\rightarrow$

Stress singularity field

(topic of this study)

Fig. 1. Overview of test for improved deformation performance under compressive stress

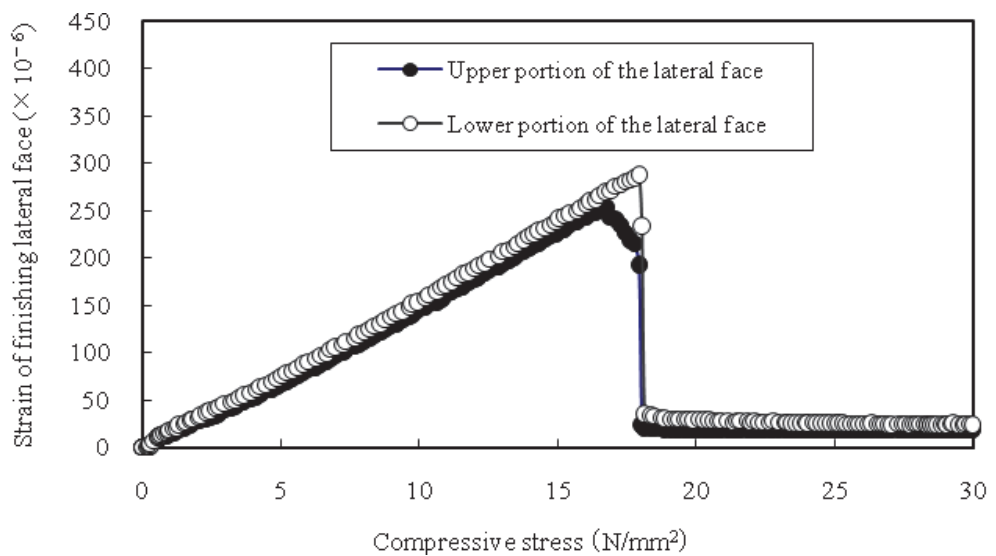

Fig. 2. Relationship between compressive stress and strains on the lateral face of a concrete sample

The purpose of this report is to propose a method for applying linear elastic interfacial fracture mechanics to problems related to the separation of cement-type materials as one method for testing simple shear stresses in ceramic tile, and to validate its practical applicability. The stress singularity parameters indicated by interfacial fracture mechanics can be handled as indicators of the interface strength for unstable fracture. If the proposed testing method is found to be practical, it could then be used in the same manner as the simple shear test when examining cement-type structure finishing products that are especially prone to separation. It may also be 
possible to extend these results to the design of the surface shapes that serve as structural interfaces in order to reduce the stresses acting on those interfaces.

\section{Stress functions applied and their solutions}

\subsection{Stress singularity field at edge of the interface between dissimilar materials in a semi-infinite region}

We will now re-draw the model of a notch in the edge of an adhesive interface between the components of a semi-infinite body composed of two dissimilar materials containing notches, which is a situation that gives rise to a stress field containing a singularity (Figure 3 ). It has previously been determined that the magnitude of stress can then be approximated by use of the logarithmic function shown in Eq. (1). Here, the parameters indicating the singularity are the order of stress singularity and the stress intensity factor. The order of stress singularity is determined by the notch angles $\theta_{1}$ and $\theta_{2}$ and the mechanical properties of the material. When both $\theta_{1}$ and $\theta_{2}$ are $180^{\circ}$, as occurs in the case of a crack, $\lambda$ is 0.5 , regardless of the material constants.

$$
\sigma \propto 1 / \mathrm{r}^{\lambda}
$$

Here, $\sigma(r)$ is the stress in the vicinity of the singularity point, $r$ is the distance from the singularity point, and $\lambda$ is the order of stress singularity.

However, Eq. (1) only provides the stress profile. It is still important to consider the stress intensity factor, which indicates the magnitude of the singularity stress field. In other words, the stress intensity factor is believed to be a function of material constants and of the shape of the bond including $\theta_{1}$ and $\theta_{2}$, but no unified theory of stress intensity factors that considers the bonded structures of differing materials has been formulated. Groth(1988),Hattori(1989, 1991) and Quaresimin(2006) expressed stress relationships as shown in Eq. (2) in order to apply Eq. (1) to practical circumstances. He expressed the stress relationship as shown in Eq. (2) for use in the practical applications of Eq. (1) and advocated using $\mathrm{K}$ as a generalized stress intensity factor when considering delamination caused by thermal stress loads. In this paper, we attempt to apply this simplified stress function to the simple shear stress test method shown in Figure 1.

$$
\sigma(\mathrm{r})=\mathrm{K} / \mathrm{r}^{\lambda}
$$

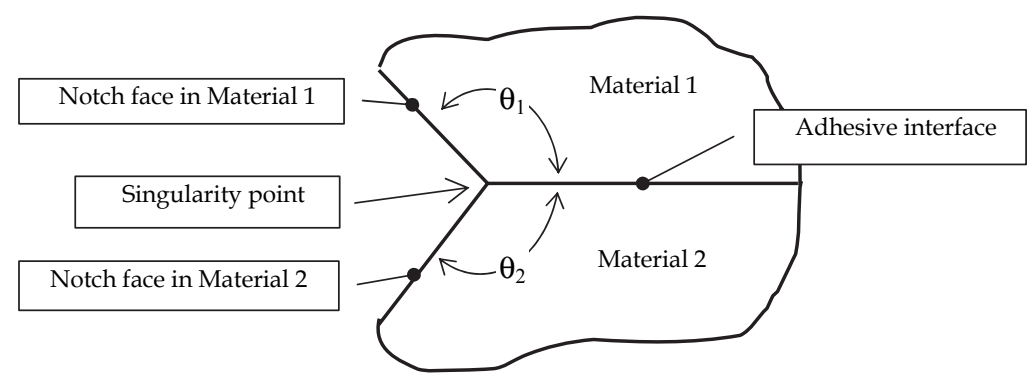

Groth(1988), Hattori(1989, 1991) and Quaresimin(2006)

Fig. 3. Model of interface between notch and dissimilar materials 


\subsection{Method for stress analysis}

In this analytical model, the simple shear strength test sample is assumed to have the material composition and shape shown in Figure 1. The one-sided half-model shown in Figure 4 was used. The sample was assumed to have the mechanical properties found in actual tests. The stress applied by the loading plate was $10 \mathrm{~N} / \mathrm{mm}^{2}$ and the boundary condition between the loading plate and the concrete was assumed to be simple contact. A numerical analysis was performed on a two-dimensional elastic body under a plane strain conditions with the stress applied by a boundary element program. The minimum element size in the vicinity of the singularity was $0.2 \mathrm{~mm}$; the material conditions are shown in Table 1. Compressive tests were carried out on concrete, cement mortar and ceramic tile and the elastic coefficients (longitudinal elasticity and Poisson's ratio) were found at $1 / 3$ the maximum level for elastic behavior for concrete and cement mortar. Because it is difficult to measure Poisson's ratio in ceramic tile samples, this value was assumed to be 0.18 .

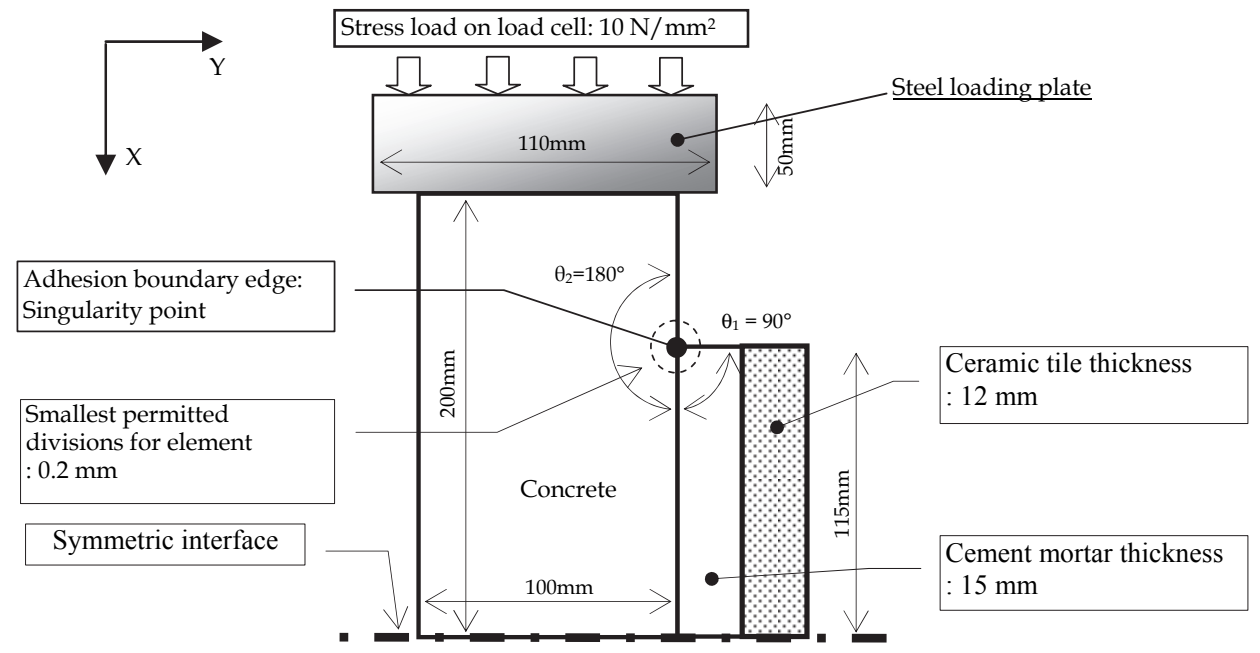

Fig. 4. Model for boundary element method

\begin{tabular}{|c|c|c|}
\hline \multirow[b]{2}{*}{ Concrete } & Shape & - Width; 100 mm, Thickness; $100 \mathrm{~mm}$, Length; $400 \mathrm{~mm}$ \\
\hline & Properties & $\begin{array}{l}\text { • Material: Ordinary concrete } \\
\text { Young's modulus; } 26700 \mathrm{~N} / \mathrm{mm}^{2} \text {, Poisson's ratio; } 0.18\end{array}$ \\
\hline \multirow[b]{2}{*}{$\begin{array}{l}\text { Cement } \\
\text { mortar }\end{array}$} & Shape & - Width; $100 \mathrm{~mm}$, Thickness; $15 \mathrm{~mm}$, Length; $230 \mathrm{~mm}$ \\
\hline & Properties & $\begin{array}{c}\cdot \text { Material: Ordinary mortar } \\
\text { Young's modulus; } 24000 \mathrm{~N} / \mathrm{mm}^{2} \text {, Poisson's ratio; } 0.22\end{array}$ \\
\hline \multirow[b]{2}{*}{ Ceramic tile } & Shape & - Width; $100 \mathrm{~mm}$, Thickness; $12 \mathrm{~mm}$, Length; $230 \mathrm{~mm}$ \\
\hline & Properties & $\begin{array}{c}\cdot \text { Material: Ordinary stoneware tile } \\
\text { Young's modulus; } 38100 \mathrm{~N} / \mathrm{mm}^{2} \text {, Poisson's ratio; } 0.18\end{array}$ \\
\hline
\end{tabular}

Table 1. Basic conditions for each layer 


\subsection{Stress field at the adhesive interface}

A log-log chart of the absolute value of each interfacial stress versus the distance $\mathrm{r}(0.5-100$ $\mathrm{mm}$ ) from the leading edge of the interface is shown in Figure 5. It was found that $\sigma_{x}$ (normal stress parallel to the interface) and $\tau$ (shear stress) varied in an approximately linear fashion within the range near the edge $(r \approx 0.5 \mathrm{~mm})$ to $\log (\mathrm{r})=0.8(\mathrm{r} \approx 7 \mathrm{~mm})$. This stress distribution indicates that it may be possible to express the stress function using Eq. (2). At distances over $7 \mathrm{~mm}$, this relationship diverges from linearity, and ultimately, the singularity disappears. Meanwhile, $\sigma_{\mathrm{y}}$ (normal stress perpendicular to the interface) does not show any such linearity, even in the region quite close to the edge (within $r=0.5$ ), and stress decreases rapidly, indicating disappearance of the singularity. These results indicate that incorrect values for the stress singularity parameters will be obtained by improper application of the linear relationship in Eq. (2) if calculations are carried out too close to the edge of the interface, or if the elements selected for numerical analysis are too coarse.

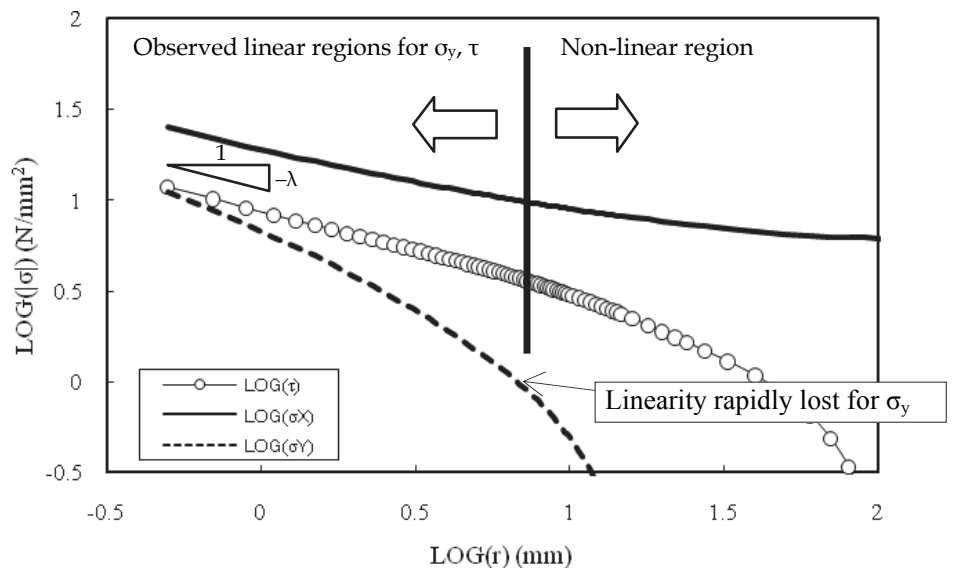

Fig. 5. Log-log graph of stress distribution (absolute values)

Two cracking modes are considered when assessing the risk of interface delamination in two-dimensional problems: Mode I (tensile stress-induced cracking) and Mode II (shearinduced cracking). These are induced by $\sigma_{\mathrm{y}}$ and $\tau$. Here, $\sigma_{\mathrm{y}}$ is a negative stress, which acts to close cracks, so Mode I fractures cannot occur. Thus, a Mode II fracture caused by shear stress $\tau$ is the only mode assumed to act during this simple shear test. Therefore, the expressions for stress as it affects the stress singularity in the present study are exclusively $\tau$, which has the chief influence over interface fracture here. The linear region of logarithmic stress in Figure 5 (up to $\mathrm{r} \approx 7 \mathrm{~mm}$ ) was divided into three sub-regions. The solutions of further least-squares analyses for each portion are presented in Table 2. Each linearization showed a close resemblance to the order of the stress singularity, but varied from it by 3 to $7 \%$. Thus, the piecewise linear data showed quite high linearity in each sub-region, but it is clear that the calculated values are vulnerable to several factors, including the choice of coarseness in the elements selected for the numerical analysis. This indicates that it is essential to develop an appropriate approach to these calculations. $K^{\prime}$ is the apparent stress intensity factor found from the approximately linear segment where $\log (r)=0$. 


\begin{tabular}{|c|c|c|c|c|}
\hline Region & $\begin{array}{c}\text { Distance } \mathrm{r} \text { from } \\
\text { edge }(\mathrm{mm})\end{array}$ & $\log (\mathrm{r})$ & $\begin{array}{c}\text { Apparent singularity } \\
\text { order: } \lambda \\
\text { (ratio with order } \\
\text { near edge) }\end{array}$ & $\begin{array}{c}\text { Apparent stress intensity } \\
\text { factor } \\
\mathrm{K}^{\prime}\left(\mathrm{N} \text { mm }{ }^{\lambda-2}\right)\end{array}$ \\
\hline A & $0.5-1.3$ & $\begin{array}{c}-0.3010 \\
\text { to } 0.1139\end{array}$ & $\begin{array}{c}0.445 \\
(1.000)\end{array}$ & $\begin{array}{c}8.57 \\
\text { (corr. coeff.: 0.9999) }\end{array}$ \\
\hline B & $1.3-3.1$ & $\begin{array}{c}0.1139 \\
\text { to } 0.4914\end{array}$ & $\begin{array}{c}0.414 \\
(0.930)\end{array}$ & $\begin{array}{c}8.52 \\
\text { (corr. coeff.: 1.0000) }\end{array}$ \\
\hline C & $3.1-6.9$ & $\begin{array}{c}0.4914 \\
\text { to } 0.8388\end{array}$ & $\begin{array}{c}0.458 \\
(1.029)\end{array}$ & $\begin{array}{c}8.95 \\
\text { (corr. coeff.: 0.9993) }\end{array}$ \\
\hline
\end{tabular}

Table 2. Results for piecewise linearization of shear stress

\section{Calculation of the stress singularity parameters}

\subsection{Calculation of the order of stress singularity}

Bogy(1971) employed the two-dimensional semi-infinite model shown in Figure 3, which incorporates Young's modulus and Poisson's ratio as $\mathrm{E}_{1}, \mathrm{v}_{1}$ and $\mathrm{E}_{2}, \mathrm{v}_{2}$ and notch angles $\theta_{1}, \theta_{2}$ for the respective materials. He derived theoretical values for $\lambda$ from the roots $p$ of the characteristic Eq. (3), which are used in Eq. (2). In this report, the stress singularity field occurring at the edge of the interface between the concrete and cement mortar layers in the finished structure is approximated with Eq. (1). It is proposed that the theoretical solutions to Bogy's characteristic equation be applied to the order of the stress singularity:

$$
\mathbf{Q}\left(\theta_{1}, \theta_{2}, \mathrm{a}, \beta ; \mathrm{p}\right)=0
$$

where the characteristic function $Q$ and coefficients are determined by the following equations:

$$
\begin{gathered}
\mathrm{Q}\left(\theta_{1}, \theta_{2}, \mathrm{a}, \beta ; \mathrm{p}\right)= \\
=\beta 2 \cdot \mathrm{A}\left(\theta_{1}, \theta_{2} ; \mathrm{p}\right)+2 \cdot \alpha \cdot \beta \cdot \mathrm{B}\left(\theta_{1}, \theta_{2} ; \mathrm{p}\right)+\mathrm{a}^{2} \cdot \mathrm{C}\left(\theta_{1}, \theta_{2} ; \mathrm{p}\right)+2 \cdot \beta \cdot \mathrm{D}\left(\theta_{1}, \theta_{2} ; \mathrm{p}\right)+2 \cdot \mathrm{\alpha} \cdot \mathrm{E}\left(\theta_{1}, \theta_{2} ; \mathrm{p}\right)+\mathrm{F}\left(\theta_{1}, \theta_{2} ; \mathrm{p}\right) \\
\mathrm{G}_{\mathrm{i}}=\mathrm{E}_{\mathrm{i}} /\left(2\left(1+\mathrm{v}_{\mathrm{i}}\right)\right) \quad(\mathrm{i}=1,2) \\
\mathrm{m}_{\mathrm{i}}=\left\{\begin{array}{l}
4\left(1-\mathrm{v}_{\mathrm{i}}\right) ; \text { plane strain } \\
4 /\left(1+\mathrm{v}_{\mathrm{i}}\right) ; \text { plane stress }
\end{array} \quad(\mathrm{i}=1,2)\right. \\
\mathrm{a}=\left(\mathrm{G}_{1} \cdot \mathrm{m}_{2}-\mathrm{G}_{2} \cdot \mathrm{m}_{2}\right) /\left(\mathrm{G}_{1} \cdot \mathrm{m}_{2}+\mathrm{G}_{2} \cdot \mathrm{m}_{1}\right) \\
\beta=\left(\mathrm{G}_{1}\left(\mathrm{~m}_{2}-2\right)-\mathrm{G}_{2}\left(\mathrm{~m}_{1}-2\right)\right) /\left(\mathrm{G}_{1} \cdot \mathrm{m}_{2}+\mathrm{G}_{2} \cdot \mathrm{m}_{1}\right)
\end{gathered}
$$

If we use

$$
\mathbf{H}(\mathrm{p}, \theta)=\sin ^{2}(\mathrm{p} \theta)-\mathrm{P}^{2} \sin ^{2}(\theta)
$$

then A-F in Eq. (4) are determined as follows: 


$$
\begin{aligned}
& \mathbf{A}\left(\theta_{1}, \theta_{2} ; \mathrm{p}\right)=4 \mathrm{H}\left(\mathrm{p}, \theta_{1}\right) \cdot \mathrm{H}\left(\mathrm{p}, \theta_{2}\right) \\
& \mathbf{B}\left(\theta_{1}, \theta_{2} ; \mathrm{p}\right)=2 \mathrm{p}^{2} \cdot \sin ^{2}\left(\theta_{1}\right) \cdot \mathrm{H}\left(\mathrm{p}, \theta_{2}\right)+2 \mathrm{p}^{2} \cdot \sin ^{2}\left(\theta_{2}\right) \cdot \mathrm{H}\left(\mathrm{p}, \theta_{1}\right) \\
& \mathbf{C}\left(\theta_{1}, \theta_{2} ; \mathrm{p}\right)=4 \mathrm{p}^{2} \cdot\left(\mathrm{p}^{2}-1\right) \cdot \sin ^{2}\left(\theta_{1}\right) \cdot \sin ^{2}\left(\theta_{2}\right)+\mathrm{H}\left\{\mathrm{p},\left(\theta_{1}-\theta_{2}\right)\right\} \\
& \mathbf{D}\left(\theta_{1}, \theta_{2} ; \mathrm{p}\right)=2 \mathrm{p}^{2}\left\{\sin ^{2}\left(\theta_{2}\right) \cdot \sin ^{2}\left(\mathrm{p} \theta_{1}\right)-\sin ^{2}\left(\theta_{1}\right) \cdot \sin ^{2}\left(\mathrm{p} \theta_{2}\right)\right\} \\
& \mathbf{E}\left(\theta_{1}, \theta_{2} ; \mathrm{p}\right)=-\mathrm{D}\left(\theta_{1}, \theta_{2} ; \mathrm{p}\right)+\mathrm{H}\left(\mathrm{p}, \theta_{1}\right)-\mathrm{H}\left(\mathrm{p}, \theta_{2}\right) \\
& \mathbf{F}\left(\theta_{1}, \theta_{2} ; \mathrm{p}\right)=\mathrm{H}\left\{\mathrm{p},\left(\theta_{1}+\theta_{2}\right)\right\}
\end{aligned}
$$

The order of stress singularity $\lambda$ is then found from the roots $\mathrm{p}$ of the above characteristic equation as follows:

$$
\lambda=1-\mathrm{p}
$$

where $\mathrm{p}$ is a real number, $0<\mathrm{p}<1$, when the singularity occurs, and $\mathrm{p} \geq 1$ when no singularity occurs.

There are cases where $\mathrm{p}$ is complex, but a detailed analysis by Hein, Erdogan and others(1971) showed clearly that $\mathrm{p}$ is always real under the mechanical conditions imposed on the materials considered in the present study, as will be described below.

The solution to the characteristic equation using a singularity point case at the edge of a finish is shown in Figure 6. Here, notch angle $\theta_{1}=90^{\circ}$ for the finish layer angle and $\theta_{2}=$ $180^{\circ}$ for the concrete adhesion angle under conditions that are otherwise identical to those for the simple shear test shown in Figure 1. Thus, the roots $p$ are found by iteration until the characteristic equation $Q$ on the left side of Eq. (3) is zero. This result indicates two values, $p$ $=0.548,0.925$, yielding $\lambda=0.452,0.075$ in Eq. (11). As shown in Table 2, values for stress singularity $\lambda$ differ depending on analytic region, and the log-log chart does not actually provide a linear solution because two orders of stress singularity $\lambda$ exist. The two stress fields of these singularities are actually superimposed on each other to produce the overall field. If the stress function is simplified as in Eq. (2), one of these $\lambda$ must be applied. Additionally, the order with the greater magnitude is believed to be dominant; this approach predicts that, of the two values for $\lambda$ given above, 0.452 would be the appropriate value to employ. This theoretical value is very close to the value for the gradient found in Table 2, 0.445, confirming that under the present analytical conditions, the theoretically predicted value for the order of stress singularity is acceptable in the vicinity of the edge of the attachment interface.

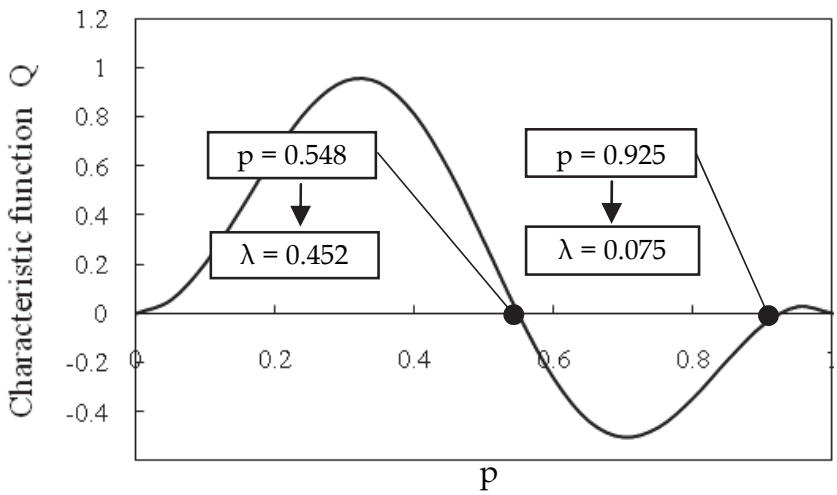

Fig. 6. Calculated characteristic function 


\subsection{Calculation of stress intensity factor at the edge of the attachment interface}

The stress intensity factor at the singularity point is estimated by direct extrapolation from adjacent values. First, Eq. (2) is re-written as Eq. (12) in order to determine $\mathrm{Kr}$ from the distance $r$ and the numerical solution for $\mathrm{\tau}$ :

$$
\operatorname{Kr}(\tau, r)=\tau \cdot r^{\lambda}
$$

where the larger of the two values found in Bogy's theoretical solution for order of stress singularity $\lambda$ is provisionally employed. This will be examined for its suitability below. The results using Eq. (12) are shown in Figure 7. The value for $\mathrm{Kr}$ is nearly linear within the first $5 \mathrm{~mm}$ from the edge of the interface. The stress intensity factor within this range $\mathrm{Kr}_{0}$ was estimated with the extrapolation formula in Eq. (13). This value was $8.52 \mathrm{~N} \mathrm{~mm} \mathrm{~m}^{\lambda-2}$, nearly the same as the apparent value given for $\mathrm{K}^{\prime}$ in Table 2.

$$
\mathrm{Kr}_{0}=\lim _{r \rightarrow 0} \operatorname{Kr}(\tau, \mathrm{r})
$$

When the stress intensity factor $\mathrm{Kr}_{0}$ and order of stress singularity $\lambda$ are calculated by the above method, the distribution of shear stress near the edge of the finish work is given by Eq. (14). The values for $\tau$ predicted by the numerical model and by Eq. (14) are compared in Figure 8; the extrapolation provided a good approximation of $\mathrm{Kr}_{0}$ within the extrapolation region.

$$
\tau(\mathrm{r})=\mathrm{Kr}_{0} / \mathrm{r}^{\lambda}
$$

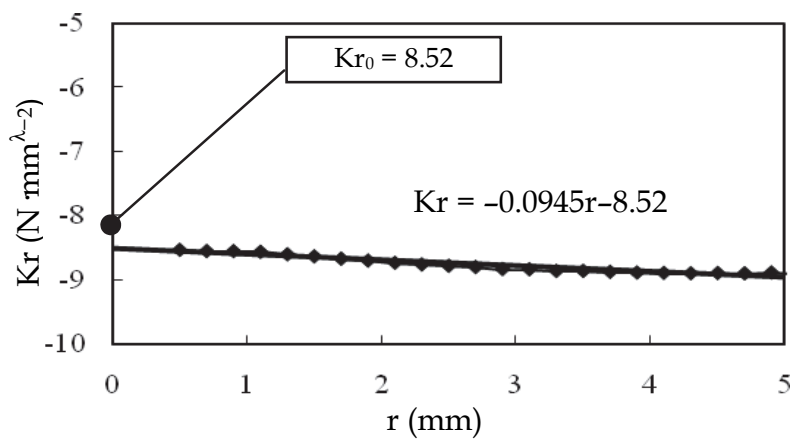

Fig. 7. Extrapolation of $\mathrm{Kr}_{0}$ (theoretical value for $\lambda$ ) 


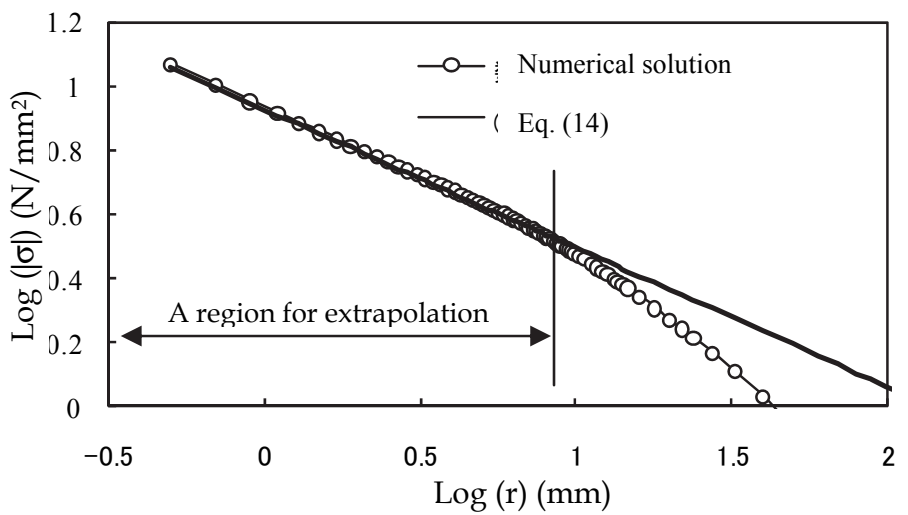

Fig. 8. Comparison of numerical solution with the solution yielded by the proposed method.

\section{Parametric analysis of finishing conditions}

\subsection{Issues under investigation}

This report examines the problem of whether the method for estimating the stress intensity factor by fitting the calculated value of the order of stress singularity in Eq. (13) to Eq. (2) is valid. There are two methods for calculating the order of stress singularity: finding the gradient with a linear approximation of the shear stress (the approximated solution) and the method proposed here, based on Bogy's theoretical analysis (the theoretical solution). The approximated solution provides an inaccurate value in the approximation region (Table 2) where there is a risk of influence on the estimate from the accuracy of the analytical method or from too-coarse elements. In contrast, the theoretical solution provides an unambiguous figure, based on the material constants and notch angles illustrated in Figure 3. This avoids the issues of the approximate approach. However, the material is thin near the edge of the adhesive interface and the situation here is very different from the semi-infinite region shown in Figure 3. For this reason, it is not clear whether the stress field takes the form predicted by the current theory. It must also be determined whether this theoretical solution should be fitted to Eq. (2) in situations where the theoretical solution provides multiple realnumber solutions. Therefore, in the present study, this calculation method is evaluated by comparing the value for the order of stress singularity found by the theoretical approach to the approximated solution in an extremely narrow region near the singularity point, which is taken as the "true" value. The stress intensity factor is a very important parameter, used in the failure criteria for the adhesive interface and in other calculations. Therefore, the method for estimating this value is assessed in the same way as was previously described for the order of stress singularity. That is, by evaluating the approximated solution in close proximity to the singularity point and comparing this result to that provided by the approach proposed in this paper. The approximated solution was obtained in Region A, which is quite close to the singularity point, as shown in Table 2. 
Both stress singularity parameters are believed to be strongly influenced by the geometrical conditions and mechanical characteristics of the finish material layer; thus, in the present study, the finish conditions are divided into three different series for separate parametric analyses.

\subsection{Analytical models and basic conditions}

The analytical conditions were defined as depth and length of the tile layer and mortar layer, as well as elastic coefficients. The typical real values of these parameters were used. The calculation methods are summarized in Figure 9. The analytical model was as shown in Figure 4, consisting of three layers: concrete, adhesive cement mortar, and ceramic tile. The model was one-sided and was symmetric about the horizontal center line. Two-dimensional plane strain analysis was used, assuming elastic media, and the boundary element method was employed. Since there was no influence on the stress singularity parameters from the loading, the same loading was used as in Figure 4, $10 \mathrm{~N} / \mathrm{mm}^{2}$. The basic conditions in each layer were also as shown in Table 1.

Analysis of stress distribution near notch using boundary element method

\section{Calculation of stress singularity parameters}

A) Approximated solution: $r$ and $\tau$ are approximated by least-squares solution in region (1) near the singularity point found in Table 1 and the slope of the $\mathrm{r}-\mathrm{\tau}$ line on a log-log plot is employed.

B) Theoretical solution: $r$ and $\tau$ are found using Bogy's theoretical solutions; the greater values are employed when multiple real solutions exist.

\section{Calculation of stress intensity factor by extrapolation}

Fig. 9. Flow chart of calculations of stress singularity parameters

\subsection{Scheme of analysis}

The three series of analytical conditions are presented in Table 3.

In Series I, the mortar layer thickness and tile layer thickness were the analytical factors. Three mortar thicknesses and four integral multiples of the tile thickness $(6 \mathrm{~mm})$ were utilized.

In Series II, the analytical factor was finish layer length. The basic dimension was the length of a standard tile $(227 \mathrm{~mm})$. Four lengths were used, 0.25 to 1.5 times the basic dimension. The materials used in the mortar layer and tile layer were the same as in Series I.

In Series III, the relevant factors were the materials used for the mortar and tile layers. The basic conditions differed from those in Table 3. In anticipation of the future use of mortar with low Young's modulus, which has been under development in recent years, one of the two types of mortar in the mortar layer was assumed to have a low Young's modulus. The tile layer was also assumed to be one of two types, either stoneware finishing tile or porcelain finishing tile (both with Young's modulus of $44800 \mathrm{~N} / \mathrm{mm}^{2}$ and Poisson's ratio of $0.18)$. 


\begin{tabular}{|c|c|c|}
\hline Series & Layer & Conditions \\
\hline \multirow{2}{*}{ I } & Ceramic tile & $\begin{array}{l}\text { Four thicknesses: 6-24 mm, Length: all standard length } 227 \mathrm{~mm} \\
\text { Material: Stoneware tile }\end{array}$ \\
\hline & Mortar & $\begin{array}{l}\text { Three thicknesses: 5-15 mm, Length: same as tile } \\
\text { Material: Ordinary mortar }\end{array}$ \\
\hline \multirow[t]{2}{*}{ II } & Ceramic tile & $\begin{array}{l}\text { Thickness: } 12 \mathrm{~mm} \\
\text { Composition of tile and joints } \\
\text { [Non-jointed configuration]: } 4 \text { lengths } \\
\text { 1) } 341 \mathrm{~mm}(1.5 \times \text { standard length) } \\
\text { 2) } 227 \mathrm{~mm} \text { (standard length) } \\
\text { 3) } 114 \mathrm{~mm}(1 / 2 \text { standard length) } \\
\text { 4) } 57 \mathrm{~mm}(1 / 4 \text { standard length) } \\
\text { [Jointed configuration]: } 2 \text { lengths } \\
\text { 1) } 2 \text { tiles }+1 \text { joint } \\
\text { (tile } 1 / 2 \text { standard length, } 1 \text { joint } 6 \mathrm{~mm} \text { long in center) } \\
\text { 2) } 3 \text { tiles }+1 \text { joint (attachment length } 354 \mathrm{~mm}) \\
\text { (tile } 1 / 2 \text { standard length, } 2 \text { joints } 6 \mathrm{~mm} \text { long in center) } \\
\text { Material: Stoneware tile }\end{array}$ \\
\hline & Mortar & $\begin{array}{l}\text { Thickness: } 15 \mathrm{~mm} \text {, Length: same as tile } \\
\text { Material: Ordinary mortar }\end{array}$ \\
\hline \multirow{2}{*}{ III } & Ceramic tile & $\begin{array}{l}\text { Thickness: } 12 \mathrm{~mm} \text {, Length: all standard length } 227 \mathrm{~mm} \\
\text { Material: } 2 \text { types, Stoneware tile and porcelain tile finishing } \\
\text { 1) Stoneware tile } \\
\text { 2) Porcelain tile } \\
\text { (Young's modulus: } 44800 \mathrm{~N} / \mathrm{mm}^{2}{ }^{2} \text {, Poisson's ratio: } 0.18 \text { ) }\end{array}$ \\
\hline & Mortar & $\begin{array}{l}\text { Two thicknesses: } 5 \text { and } 15 \mathrm{~mm} \text {, Length: same as tile } \\
\text { Material: Ordinary mortar and light mortar } \\
\text { 1) Ordinary mortar } \\
\text { 2) Two types of light mortar } \\
\text { (1/2 and } 1 / 4 \text { longitudinal Young's modulus of ordinary mortar) }\end{array}$ \\
\hline
\end{tabular}

* All widths $100 \mathrm{~mm}$

Table 3. Analytical Conditions

\subsection{Results of analysis for shear stress distribution}

\subsubsection{Series I}

The results of this analysis are shown in Table 4. Almost no influence from the mortar or tile thickness was observed on the order of stress singularity in the approximated solution. The variation in the theoretical solution was small at $1-5 \%$. The theoretical solution appears to be capable of predicting the order of stress singularity with adequate accuracy.

Variation in the calculated stress intensity factor versus finish layer thickness, the sum of mortar thickness and tile thickness is shown in Figure 10. The stress intensity factor increased gradually with tile thickness at all mortar layer thicknesses. This increase was most marked in the 5-mm mortar layer; above the finish thickness of $20 \mathrm{~mm}$; however, it remained generally constant within the range $7-8 \mathrm{~N} \mathrm{~mm}^{\lambda-2}$. No large variations were seen in the stress intensity factor under these analytical conditions. The stress intensity factor also showed extremely little variation with the method of calculation of stress singularity order. 


\begin{tabular}{|c|c|c|c|c|c|c|c|}
\hline \multirow{2}{*}{$\begin{array}{l}\text { Mortar } \\
\text { thickness } \\
(\mathrm{mm})\end{array}$} & \multirow{2}{*}{$\begin{array}{c}\text { Tile } \\
\text { thickness } \\
(\mathrm{mm})\end{array}$} & \multicolumn{2}{|c|}{$\begin{array}{l}\text { Stress singularity } \\
\text { parameters by } \\
\text { approximated } \\
\text { solution }\end{array}$} & \multicolumn{2}{|c|}{$\begin{array}{l}\text { Stress singularity } \\
\text { parameters by } \\
\text { theoretical solution }\end{array}$} & \multicolumn{2}{|c|}{$\begin{array}{l}\text { Compared theoretical } \\
\text { and approximated } \\
\text { solutions }\end{array}$} \\
\hline & & \begin{tabular}{|c|} 
Order of \\
stress \\
singularity \\
$\lambda$ \\
\end{tabular} & $\begin{array}{c}\text { Stress } \\
\text { intensity } \\
\text { factor }^{* 1} \\
\mathrm{~K} \\
\end{array}$ & $\begin{array}{c}\text { Order of } \\
\text { stress } \\
\text { singularity } \\
\lambda^{\prime} \\
\end{array}$ & $\begin{array}{c}\text { Stress } \\
\text { intensity } \\
\text { factor }^{* 1} \\
\mathrm{~K}^{\prime} \\
\end{array}$ & $\lambda^{\prime} / \lambda$ & $\mathrm{K}^{\prime} / \mathrm{K}$ \\
\hline \multirow{4}{*}{5} & 6 & 0.444 & 7.89 & \multirow{12}{*}{0.452} & 7.87 & 1.018 & 0.997 \\
\hline & 12 & 0.437 & 8.59 & & 8.54 & 1.034 & 0.994 \\
\hline & 18 & 0.434 & 8.87 & & 8.81 & 1.041 & 0.993 \\
\hline & 24 & 0.431 & 8.89 & & 8.89 & 1.049 & 1.000 \\
\hline \multirow{4}{*}{10} & 6 & 0.450 & 8.18 & & 8.18 & 1.004 & 1.000 \\
\hline & 12 & 0.444 & 8.49 & & 8.47 & 1.018 & 0.998 \\
\hline & 18 & 0.442 & 8.63 & & 8.60 & 1.023 & 0.997 \\
\hline & 24 & 0.439 & 8.66 & & 8.62 & 1.030 & 0.995 \\
\hline \multirow{4}{*}{15} & 6 & 0.449 & 8.37 & & 8.36 & 1.007 & 0.999 \\
\hline & 12 & 0.445 & 8.51 & & 8.52 & 1.016 & 1.001 \\
\hline & 18 & 0.443 & 8.59 & & 8.56 & 1.020 & 0.997 \\
\hline & 24 & 0.441 & 8.58 & & 8.55 & 1.025 & 0.997 \\
\hline
\end{tabular}

${ }^{*}$ 1) Unit: $\mathrm{N} \cdot \mathrm{mm}^{\lambda-2}$

Table 4. Analytical Results (Series I)

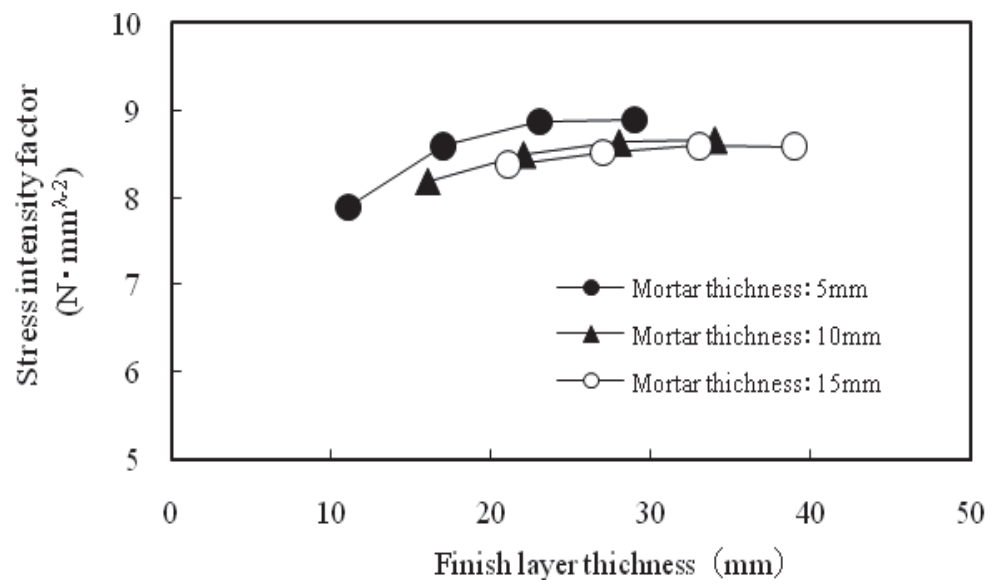

Fig. 10. Relationship between finish layer thickness and stress intensity factor (Series I)

\subsubsection{Series II}

The results were similar to those in Series I (see Table 5). No finish length influence was seen on order of stress singularity in the approximated solution method, which showed nearly the same values as the theoretical solution. 


\begin{tabular}{|c|c|c|c|c|c|c|c|}
\hline \multirow{2}{*}{$\begin{array}{l}\text { Mortar } \\
\text { thickness } \\
(\mathrm{mm})\end{array}$} & \multirow{2}{*}{$\begin{array}{c}\text { Tile } \\
\text { length } \\
\text { (times) }\end{array}$} & \multicolumn{2}{|c|}{$\begin{array}{l}\text { Stress singularity } \\
\text { parameters by } \\
\text { approximated solution }\end{array}$} & \multicolumn{2}{|c|}{$\begin{array}{c}\text { Stress singularity } \\
\text { parameters } \\
\text { by theoretical solution }\end{array}$} & \multicolumn{2}{|c|}{$\begin{array}{c}\text { Compared } \\
\text { theoretical and } \\
\text { approximated } \\
\text { solutions }\end{array}$} \\
\hline & & $\begin{array}{c}\text { Order of } \\
\text { stress } \\
\text { singularity } \\
\lambda_{a} \\
\end{array}$ & $\begin{array}{c}\text { Stress } \\
\text { intensity } \\
\text { factor }{ }^{* 1} \\
\mathrm{~K}_{\mathrm{a}} \\
\end{array}$ & $\begin{array}{c}\text { Order of } \\
\text { stress } \\
\text { singularity } \\
\lambda_{\mathrm{b}} \\
\end{array}$ & $\begin{array}{c}\text { Stress } \\
\text { intensity } \\
\text { factor }^{* 1} \\
\mathrm{~K}_{\mathrm{b}} \\
\end{array}$ & $\lambda_{\mathrm{B}} / \lambda_{\mathrm{A}}$ & $\mathrm{K}_{\mathrm{B}} / \mathrm{K}_{\mathrm{A}}$ \\
\hline \multirow{4}{*}{5} & 1.5 & 0.438 & 8.68 & \multirow{8}{*}{0.452} & 8.63 & 1.032 & 0.994 \\
\hline & 1.0 & 0.437 & 8.64 & & 8.54 & 1.032 & 0.988 \\
\hline & 0.5 & 0.443 & 8.54 & & 8.50 & 1.020 & 0.995 \\
\hline & 0.25 & 0.438 & 7.24 & & 7.20 & 1.032 & 0.994 \\
\hline \multirow{4}{*}{15} & 1.5 & 0.445 & 8.61 & & 8.58 & 1.016 & 0.996 \\
\hline & 1.0 & 0.445 & 8.51 & & 8.52 & 1.016 & 1.001 \\
\hline & 0.5 & 0.446 & 8.33 & & 8.31 & 1.013 & 0.998 \\
\hline & 0.25 & 0.424 & 6.83 & & 6.76 & 1.066 & 0.990 \\
\hline
\end{tabular}

*1) Unit: $\mathrm{N}$ mm ${ }^{\lambda-2}$

\section{Table 5. Analytical Results (Series II)}

Variation in the stress intensity factor with finish length is shown in Figure 11. The stress intensity factor was nearly constant at finish lengths over $100 \mathrm{~mm}$, but was lower at the finish length of $57 \mathrm{~mm}$. This indicates that when the finish material length is extremely small, the shear stresses operating on the interface are quite low, but at greater adhesion lengths, this low shear stress should not be assumed, as it could lead to dangerous underestimates. Despite this, when the finish length is greater than $100 \mathrm{~mm}$, the obtained stress intensity

factor figures appear to be useful. It is also important to note that the differences between the approximated solution and the theoretical solution were quite small.

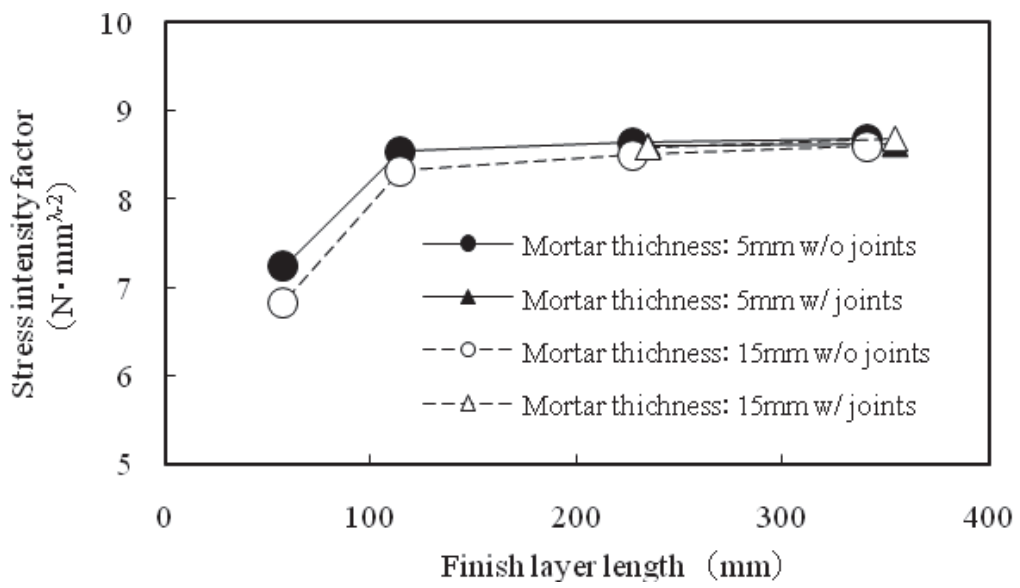

Fig. 11. Relationship between finish layer length and stress intensity factor (Series II) 


\subsubsection{Series III}

The approximated solution indicated a strong effect of Young's modulus on the predicted order of stress singularity (see Table 6). That is, the lower the Young's modulus of the mortar, the lower the order of stress singularity. In addition, it was found that as the Young's modulus of the mortar decreased, the difference between the predictions of the approximated solution and the theoretical solution became larger; this difference also

\begin{tabular}{|c|c|c|c|c|c|c|c|}
\hline \multirow{2}{*}{$\begin{array}{l}\text { Mortar } \\
\text { material }\end{array}$} & \multirow{2}{*}{ Tile material } & \multicolumn{2}{|c|}{$\begin{array}{c}\text { Stress singularity } \\
\text { parameters by } \\
\text { approximated solution }\end{array}$} & \multicolumn{2}{|c|}{$\begin{array}{l}\text { Stress singularity } \\
\text { parameters by } \\
\text { theoretical solution }\end{array}$} & \multicolumn{2}{|c|}{$\begin{array}{c}\text { Compared } \\
\text { theoretical and } \\
\text { approximated } \\
\text { solutions }\end{array}$} \\
\hline & & $\begin{array}{c}\text { Order of stress } \\
\text { singularity } \\
\lambda_{\mathrm{A}}\end{array}$ & \begin{tabular}{|c} 
Stress \\
intensity \\
factor $^{* 1}$ \\
$\mathrm{~K}_{\mathrm{a}}$
\end{tabular} & $\begin{array}{c}\text { Order of } \\
\text { stress } \\
\text { singularity } \\
\lambda_{\mathrm{b}}\end{array}$ & $\begin{array}{c}\text { Stress } \\
\text { intensity } \\
\text { factor }^{* 1} \\
\mathrm{~K}_{\mathrm{b}}\end{array}$ & $\lambda_{\mathrm{B}} / \lambda_{\mathrm{A}}$ & $\mathrm{K}_{\mathrm{B}} / \mathrm{K}_{\mathrm{A}}$ \\
\hline \multirow{2}{*}{ Ordinary } & Stoneware & 0.437 & 8.64 & \multirow{2}{*}{0.452} & 8.54 & 1.034 & 0.988 \\
\hline & Porcelain & 0.433 & 8.80 & & 8.73 & 1.044 & 0.992 \\
\hline \multirow{2}{*}{ Light (1/2) } & Stoneware & 0.372 & 6.24 & \multirow{2}{*}{0.400} & 6.16 & 1.075 & 0.987 \\
\hline & Porcelain & 0.365 & 6.42 & & 6.32 & 1.096 & 0.984 \\
\hline \multirow{2}{*}{ Light (1/4) } & Stoneware & 0.288 & 4.24 & \multirow{2}{*}{0.347} & 4.13 & 1.205 & 0.974 \\
\hline & Porcelain & 0.275 & 4.36 & & 4.21 & 1.262 & 0.966 \\
\hline
\end{tabular}

*1) Unit: $\mathrm{N} m \mathrm{~mm} \lambda-2$

Table 6. (1) Analytical Results (Series III · Mortar thickness $5 \mathrm{~mm}$ )

increased with decreasing thicknesses of the mortar layer and increases in the Young's modulus of the tile. This is attributed to an increasing constraint on mortar deformation by the tile, which has a high Young's modulus that prevents the stress field from acting as predicted theoretically. Still, the discrepancy in order of stress singularity due to the calculation method remained within $5 \%$. If this is the only parameter used to assess the risk of delamination, the method used to estimate the order of stress singularity will not be an issue.Variation in the predicted stress intensity factor with the ratio of Young's modulus (modulus of light mortar versus modulus of ordinary mortar) is shown in Figure 12. The tile material showed little influence, but reducing the ratio of Young's modulus lowered the ratio of stress intensity factor, resulting in a prediction of moderation in the resulting stress. This is a benefit of the development and use of lower-modulus mortars as a technique to prevent tile delamination. However, if used, it will also be necessary to compare the benefit of fracture toughness and other factors with that of the increased interface strength.

Lastly, in each of these series, the influence of the method of calculating order of stress singularity on the obtained values for stress intensity factor was minor. The extrapolation method proposed in the present study for finding the parameters was determined to provide acceptable accuracy across a wide range of finish attachment conditions. 


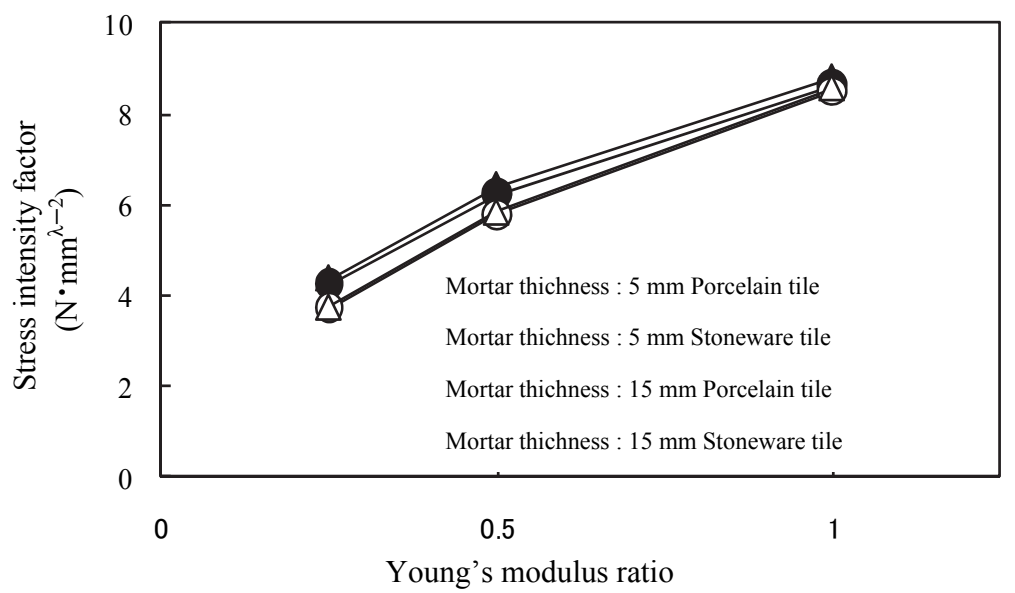

Fig. 12. Relationship between Young's modulus ratio and stress intensity factor (Series III)

\section{Conclusion}

A method was proposed for assessing the characteristics of the stress singularity field acting on the adhesive holding cement mortar structural finishing components on to concrete, and this method was analyzed. The method employed for testing finishing components was the simple shear test for ceramic tiles using axial compressive loads. The following results were obtained:

1. The various stress modes occurring during the simple shear test near the edge of the adhesive interface between concrete and mortar make up a stress field that contains a singularity point at its tip. The failure mode at the adhesive interface appears to be Mode II.

2. There are two real solutions to Bogy's theoretical solution. The stress field showed results that are fairly well approximated by the theoretical solution of greater magnitude, but in the strict sense, the stress field is complicated because it is influenced simultaneously by two orders of stress singularity.

3. Calculations of the stress intensity factor using an extrapolation method fitted to a generalized stress function revealed results that closely resembled those provided by numerical analysis.

4. The parametric analysis based on practical finishing conditions showed little influence of the geometry of the finish layer on the orders of stress singularity indicated by the approximated solution and the theoretical solution, but considerable influence of the Young's modulus ratio of mortar types. There are limits to the validity of the theoretical solution. The two solutions also provided consistent predictions for the stress intensity factor, regardless of the finish conditions. Thus, the approach proposed here was shown to provide useful data.

5. The thickness and length of the tile and mortar were also found to exert little influence on the stress singularity parameters within the range of practical dimensions. However, the Young's modulus ratio of mortar types did have a significant affect on these parameters. This analysis reproduced the stress moderating effect of low-modulus mortar. 


\section{References}

Groth, H.L. (1988). Stress singularities and fracture at interface corners in bonded joints, International Journal of Adhesion and Adhesive, Vol.8, pp. 107-113, ISSN 0143-7496.

Bogy, D.B. (1971). Two edge bonded elastic wedges of different materials and wedge angles under surface tractions, Journal of Applied Mechanics, Vol.38, pp. 377-386, ISSN 00218936.

Hein, V.L. \& Erdogan, F. (1971). Stress singularity in a two materials wedge, International Journal of Fracture, Vol.7, No.3, pp. 317-329, ISSN 0376-9429.

Quaresimin M \& Ricotta M. (2006). Life prediction of bonded joints in composite materials, International Journal of Fatigue, Vol.28, pp.1166-76, ISSN 0142-1123.

Hattori T, Sakata S, Murakami G (1989). A stress singularity parameter approach for evaluating adhesive strength, Journal of Electronic Packaging ASME, Vol.111, pp.243-248, ISSN 1528-9044.

Hattori T (1991). A stress-singularity-parameter approach for evaluating the adhesive strength of single-lap joints, Jsme International Journal Series A, Vol.34-3, pp.326331, ISSN 1347-5363. 


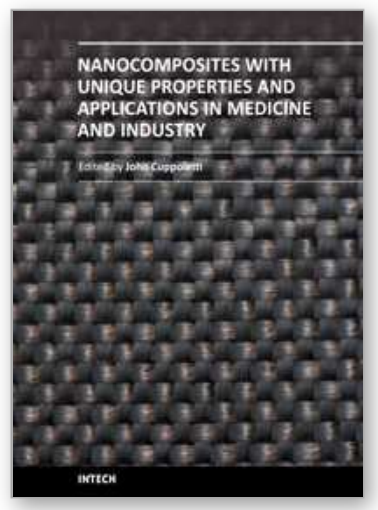

\section{Nanocomposites with Unique Properties and Applications in Medicine and Industry}

Edited by Dr. John Cuppoletti

ISBN 978-953-307-351-4

Hard cover, 360 pages

Publisher InTech

Published online 23, August, 2011

Published in print edition August, 2011

This book contains chapters on nanocomposites for engineering hard materials for high performance aircraft, rocket and automobile use, using laser pulses to form metal coatings on glass and quartz, and also tungsten carbide-cobalt nanoparticles using high voltage discharges. A major section of this book is largely devoted to chapters outlining and applying analytic methods needed for studies of nanocomposites. As such, this book will serve as good resource for such analytic methods.

\section{How to reference}

In order to correctly reference this scholarly work, feel free to copy and paste the following:

Tsugumichi Watanabe (2011). Analytical Research on Method for Applying Interfacial Fracture Mechanics to Evaluate Strength of Cementitious Adhesive Interfaces for Thin Structural Finish Details, Nanocomposites with Unique Properties and Applications in Medicine and Industry, Dr. John Cuppoletti (Ed.), ISBN: 978-953-307351-4, InTech, Available from: http://www.intechopen.com/books/nanocomposites-with-unique-properties-andapplications-in-medicine-and-industry/analytical-research-on-method-for-applying-interfacial-fracturemechanics-to-evaluate-strength-of-ce

\section{INTECH}

open science | open minds

\section{InTech Europe}

University Campus STeP Ri

Slavka Krautzeka 83/A

51000 Rijeka, Croatia

Phone: +385 (51) 770447

Fax: +385 (51) 686166

www.intechopen.com

\section{InTech China}

Unit 405, Office Block, Hotel Equatorial Shanghai

No.65, Yan An Road (West), Shanghai, 200040, China

中国上海市延安西路65号上海国际贵都大饭店办公楼 405 单元

Phone: +86-21-62489820

Fax: +86-21-62489821 
(C) 2011 The Author(s). Licensee IntechOpen. This chapter is distributed under the terms of the Creative Commons Attribution-NonCommercialShareAlike-3.0 License, which permits use, distribution and reproduction for non-commercial purposes, provided the original is properly cited and derivative works building on this content are distributed under the same license. 